\title{
Expression of p63 Protein to Differentiate Benign Prostatic Hyperplasia and Carcinoma of Prostate in Pakistani Population
}

\author{
Bushra Nisar, ${ }^{1}$ Naureen Sarwar, ${ }^{2}$ Sadia Sharif, ${ }^{3}$ Asim Hameed, ${ }^{4}$ Shazia Naz $^{5}$
}

\section{Abstract}

Background: Prostate cancer is the world's foremost and second cause of cancer associated death typically in males after lung cancer. Histopathological diagnosis of prostatic hyperplasia and prostatic carcinoma can be challenging. The expression of p63 can be used in diagnosis and differentiation of benign pro-static hyperplasia from carcinoma of prostate.

Materials and Methods: We studied sixty prostatic biopsies obtained by TURP and radical prostatectomy. For each case, clinical data was collected. The tissue sections were then diagnosed on basis of routine hematoxylin and eosin. Then immunohistochemical (IHC) analysis was performed on routinely processed, formalin-fixed, paraffin embedded tissue. We also analyzed

\footnotetext{
${ }^{1}$ Assistant Professor of Histopathology

Sheikh Zayed Medical College and Hospital Rahimyar-Khan

${ }^{2}$ Assistant Professor and Head Operative Dentistry

Akhter Saeed Medical and Dental College, Lahore

${ }^{3}$ Assistant Professor of Histopathology,

AmnaInayat Medical and Dental College, Sheikhupura

${ }^{4}$ Medical Superintendent

Govt. Muhammad Nawaz SharifTeahingHospital, Yakki Gate Lahore

${ }^{5}$ Assistant Professor of Operative Dentistry,

Demontmorency Dental College, Lahore
}

Date of Submission: 28-1202016

Date of $1^{\text {st }}$ Revision Received: 28-02-2017

Date of Acceptance for Publication: 03-05-2017

Conflict of Interest: None

Funding Source: None

\section{Contribution}

All Authors have contributed in Study Design, Data Collection, Data Analysis, Data Interpretation, Manuscript Writing and Approval.
P63 expression in regions of benign prostatic hyperplasia and prostatic adenocarcinoma. Moreover, detailed examination of tissue sections was observed with light microscopy.

Results: Mean age of patients with adenocarcinoma was $70 \pm 12$ years however mean age in prostate hyperplasia cases was $66 \pm 8$ years. With the use of Receiver Operative Characteristic Curve (ROC), the optimal cut point found of PSA was $30.0 \mathrm{ng} / \mathrm{ml}$. The results showed that prostate specific antigen (PSA) at this cutoff had a sensitivity of $71.4 \%$, with specificity of $74.4 \%$ and accuracy of $73.3 \%$. So PSA could not be considered reliable independently for the diagnosis of carcinoma of prostate. Benign cases in the present study were exclusively positive for immunohistochemical expression of p63 while all the cases of prostatic carcinomas expressed negative pattern of staining.

Conclusion: Immunostaining with p63 is useful to differentiate benign prostatic hyperplasia from prostatic carcinoma, so it may be used as valuable tool in the diagnosis of prostatic carcinoma.

Keywords: p63, prostate carcinoma, benign prostatic hyperplasia, prostate specific antigen (PSA).

\section{Introduction}

Prostatic hyperplasia is common disorder characterized by enlargement of prostate. ${ }^{1,2}$ It exhibits increase in number of cells of epithelium and prostrate stroma, thus forming large and fairly discrete nodules. ${ }^{3}$ It involves transitional and periurethral zones of prostate glands and is most progressive manifestation of elderly men above 50 years of age. ${ }^{1}$ Hyperplasia of prostate subsequently leads to the problems of lower urinary tract (outflow) symptoms in males. Anatomic bladder outlet obstruction in men results most commonly over 70 yrs. $^{4,5}$ 
Prostate cancer frequency ratio is growing worldwide. $^{6}$ Age related incidence rates of prostate cancer are diverse in different parts of world. ${ }^{2}$ In Asia, the frequency is estimated three to eleven per 100,000 persons in one year, whereas incidence among African - Americans is maximum approximately 185.4 per 100,000 persons per year. ${ }^{7}$ In Karachi, Pakistan incidence and trend of prostate cancer were reviewed from 1995 to1997 and 1998 to 2002 . Cancer of prostate was established in roughly 3.4 percent of males from year 1995 till 1997, and graded eighth with ASR (Age standardized incidence) rate per 100,000 of 6.0 and 2.8 respectively. ${ }^{8}$ During the period of $1998-2002$, prostate cancer accounted for 4.6 percent, and ranked fourth with an ASR world and CIR per 100,000 of 10.1 and 4.4. Approximately there was a $60 \%$ increase observed from 1995 and 2002.Incidence of prostate cancer in Pakistan is $3-7$ per 100,000 persons/years from 1994 to 2004 . $^{9}$

The discovery of p63 as basal cell marker makes it a beneficial stain in challenging cases to differentiate prostatic hyperplasia from prostatic carcinoma. ${ }^{9,10}$ Immuno-histochemically nuclear protein p63 is diagnostically consistent in authenticating basal cells. ${ }^{2,10} \mathrm{In}$ prostate needle biopsies, radical prostatectomy and transurethral resection of prostate (TURP) specimens. The protein (p63) has been identified as an important homologue of the tumor suppressor protein. ${ }^{11}$ It has an important role in regulating growth and development of the urogenital system, epithelium of the salivary gland, skin, cervix, breast and particularly prostate. ${ }^{12}$ It has an imperative role in regulation of differentiation programs and epithelial proliferation. ${ }^{11,12}$

In 2012 Chastain and Oliva examined p63 as an additional indicator especially used for basal cells with High Molecular Weight-Cytokeratin (HMW-CK). ${ }^{13}$ HMW-CK antigen shows absence of basal cell staining due to effect of prolonged formalin fixation which results in patchy staining/absent basal cells in benign glands. ${ }^{6}$ Currently antibodies of p63 are established more sensitive as compared to HMW-CK for basal cells identification in prostate. ${ }^{2}$ Specificity, sensitivity, and positive predictive value for p63 and HMW-CK have been considered for detection of basal cells in benign prostate glands. ${ }^{9}$ The specificity for both markers, was 100 percent and the sensitivity of p63 and HMW-CK were 88.37 percent and 96.70 percent correspondingly. ${ }^{13}$ A study reported the effectiveness of immunohistochemical investigation by p63 (basal cell specific marker) and confirmed prostatic cancer by negative staining pattern. ${ }^{6}$ So, p63 immunostaining is reliable in diagnosing basal cells in benign lesions and does not give false positive result in prostatic biopsies. $^{8}$ In local population, expression of P63 and its potential use for diagnosis of prostate hyperplasia has not been reported. Present study was designed to investigate the expression of p63 in benign prostatic hyperplasia versus prostatic carcinoma. This may help to improve early detection of hyperplasia, improve clinical practice and decrease preventable surgical procedures and morbidities.

\section{Materials and Methods}

Study Duration: The duration of this study was from 03-07-2013 to 31-12-2013.

Sample Size: Sample size of 60 patients was taken in this study.

Sampling Technique: Non-Probability, Purposive Sampling.

\section{Sample Selection}

\section{Inclusion Criteria}

1. Prostate specimens obtained either by Trans Urethral Resection prostate (TURP) or Radical prostatectomy.

2. Prostate specimens of male patients over age 40 years.

3. Patients whose data of PSA level is available.

4. Patients who give consent.

\section{Exclusion Criteria}

1. Scanty or inadequate biopsy material.

2. Improperly preserved or processed tissue.

3. Patients receiving / already received chemotherapy, radiotherapy or hormone therapy.

4. Recurrent cases of prostate cancer.

\section{Acquisition of Specimens}

After informed consent biopsy specimens of 60 patients undergoing various diagnostic and/or surgical resection procedures for hyperplasia and carcinoma of the prostate were acquired from Urology Ward of Lahore General Hospital, Lahore. Approval of study was taken from ethical committee General hospital, Lahore. Surgical tissues were obtained by radical prostatectomy specimens, transurethral resection of prostate (TURP) and ultra sound guided (USG) guided 
needle core biopsies. All specimens were placed in adequate amount of $10 \%$ formalin solution.

\section{Clinical Details}

Socio-demographic information (name, age, full address, history of frequency and urgency of micturition, family history of any cancer and prostate cancer) were obtained along with data of PSA level. All the information was recorded on specially designed proforma. In hyperplasia of the prostate, predominant persistent brown nuclear staining was present and all the carcinomas of the prostate showed negative staining for $\mathrm{p} 63$.

The data was entered and analyzed by SPSS version 20. Data for age, size of prostate and PSA levels was described by using frequency distribution as well as Mean \pm SD. Results of p63 immunostaining expression and clinical symptoms were all described by using frequency and percentage. The comparison of age, PSA level, all clinical symptoms and p63 results between adenocarcinoma and hyperplasia groupswere made by using Chi-square test. ROC curve was used to see the reliability of PSA level as a diagnostic tool against p63. Sensitivity, specificity, positive predictive value, negative predictive value and diagnostic accuracy of PSA were presented by using percentage with $95 \%$ confidence interval. A $p$-value $\leq 0.05$ was considered as statistically significant.

\section{Results}

Sixty cases of benign prostatic hyperplasia and carcinoma of prostate were included in study. The average age of patients was $67+10$ years in range from $35-$ 95 years. Three (5.0 percent) cases had age lower than 50 years and twelve cases (20.0 percent) were between $51-60$ years of age. Age of most patients ranged from $61-80$ years with exclusion of one patient whose age was above ninety years. Average PSA levels noted for sixty cases was $46.1 \pm 91.9 \mathrm{ng} / \mathrm{ml}$ ranging from $4.0-$ 625.0. Lesions having PSA level $\leq 15.0 \mathrm{ng} / \mathrm{ml}$ were twenty two (36.7 percent). PSA levels more than 75 $\mathrm{ng} / \mathrm{ml}$ was merely in five cases (8.3percent) and most of cases $27(45.0 \%)$ had levels ranging between 15 and $45 \mathrm{ng} / \mathrm{ml}$. Most (60.0\%) of the cases had weight of prostate between 10 and 20 grams, with 11 (18.3\%) cases between 5 and 10 grams. There were 5(8.3\%) cases below $5 \mathrm{gm}$ and $3(5.0 \%)$ had weight of prostate above 30 grams with maximum weight 60.0 grams.
The mean weight recorded for the cases was $16.1 \pm$ 9.4g.

Among these cases 16 (26.7\%) had no micturition frequency, $14(23.3 \%)$ had mild while $20(33.3 \%)$ and $10(16.7 \%)$ had moderate and severe frequency of micturition. Similarly the history of urine retention was absent in $11(18.3 \%)$ cases. Mild retention history was found in $22(36.7 \%)$ cases with $18(30.0 \%)$ and 9 $(15.0 \%)$ cases had history of moderate and severe retention. Among other clinical symptoms burning was the major issue found in $35(58.3 \%)$ cases while 15 $(25.0 \%)$ cases had hematuria and $3(5.0 \%)$ cases did not have any other symptom present. Most of the prostatic biopsies were TURP and only 3 were RADICAL type. On H\&E examination $21(35.0 \%)$ cases were diagnosed with adenocarcinoma and remaining 39 $(65.0 \%)$ with hyperplasia of prostate. When these cases were analyzed with P63 immunostaining it was noted that 21 cases with adenocarcinoma had negative pattern on P63 stains and 39 cases of hyperplasia were positive showing persistent brown nuclear staining. Sensitivity and specificity of P63 was observed $100.0 \%$. In comparison of cases of carcinoma and hyperplasia of the prostate, age distribution with pvalue 0.227 was not significantly different. The only exception found that is insignificant, carcinoma beyond 80 years of age was noted in three cases although no case of hyperplasia was identified at this age. The PSA level was significantly different between two groups with p-value 0.002 . The mean value for adenocarcinoma group was $91.6 \pm 145.2$ and that for the hyperplasia was $21.5 \pm 15.3$. In hyperplasia group almost $75.0 \%$ cases had PSA levels below $30 \mathrm{ng} / \mathrm{ml}$ while in carcinoma cases $33.3 \%$ had between 30 and 45 and $23.8 \%$ cases had above $75.0 \mathrm{ng} / \mathrm{ml}$.

The weight of prostate was not seen to be significantly different between cases in two groups. The distribution was same with average weight of $14.2 \pm 7.4$ and $17.1 \pm 10.2$ grams in adenocarcinoma and hyperplasia groups respectively with p-value 0.628 .

On comparison it was noted that the micturition frequency was not present in most $(76.2 \%)$ of adenocarcinoma cases, but to some extent this symptom was present in all cases of prostatic hyperplasia so the $\mathrm{p}$ value noted here was $<0.00$. In the same manner the adenocarcinoma cases either had no history of retention of urine $(47.6 \%$ cases) or showed history of very considerable retention ( $47.6 \%$ cases). Whereas in case of hyperplasia of prostate single patient complaint of retention whereas $67 \%$ complained of moderate to 
severe retention of urine. Difference was proved to be significant again with $\mathrm{p}$-value $<0.001$.

Among other clinical symptoms, burning micturition was the major issue present only in hyperplasia cases and was present in $89.7 \%$ cases. Hematuria was the problem found only in adenocarcinoma cases and found in $71.4 \%$ of cases. This difference was highly significant between two groups with $\mathrm{p}$-value $<0.001$. In the end when cutoff of PSA was searched by receiver operative characteristic curve (ROC), the optimal point found was $30.0 \mathrm{ng} / \mathrm{ml}$. The diagnosis showed that PSA at this cut off had a sensitivity of $71.4 \%$, with specificity of $74.4 \%$ and accuracy of $73.3 \%$. So could not be considered reliable independently.

Table 1: Reliability of PSA level as diagnostic tool for prostatic carcinoma on the basis of diagnostic measures.

\begin{tabular}{|l|c|c|}
\hline Measure & Value & $\begin{array}{c}\text { 95\% Confidence } \\
\text { Interval }\end{array}$ \\
\hline Sensitivity & 71.4 & $60.0-82.8$ \\
\hline Specificity & 74.4 & $63.4-85.4$ \\
\hline Positive Predictive Value & 60.0 & $47.6-72.4$ \\
\hline Negative Predictive Value & 82.9 & $73.4-92.4$ \\
\hline Accuracy & 73.3 & $62.1-84.5$ \\
\hline
\end{tabular}

\section{Discussion}

For screening of prostate cancer, PSA level was considered the screening tool since mid-1980s. Currently annual digital rectal examination (DRE) and serum PSA level determination are recommended screening measures for carcinoma of prostate. The normal PSA value is considered to be $4.0 \mathrm{ng} / \mathrm{ml}$, the borderline value ranges from $4-10 \mathrm{ng} / \mathrm{ml}$ while higher than $10 \mathrm{ng} / \mathrm{ml}$ was believed to be high level. Cases with PSA value more than $4 \mathrm{ng} / \mathrm{ml}$ despite DRE results, biopsy is required to reach the final diagnosis. Highest specificity was considered to be maximum in males omitted without prostatic cancer whereas highest sensitivity was considered to be maximum number of prostatic cancer findings. Highest specificity and highest sensitivity are present at cut off value of $4.0 \mathrm{ng} / \mathrm{ml} .^{14}$ PSA is highly expressed in both benign prostatic epithelia and prostate cancer cells. ${ }^{15}$

Basic hematoxylin and eosin (H\&E) staining criteria are used for morphological assessment of benign and carcinoma cases of prostate. ${ }^{16}$ Malignancy features are diagnosed easily on the basis of infiltrative glands lined by luminal cells with increase in nucleolar and nuclear size and absence of basal cells. ${ }^{17}$ Numerous auxiliary techniques have been suggested for the recognition of malignancy. The role of immunohistochemistry is very important to differentiate the lesions. ${ }^{18}$

For this study, average PSA level for 60 cases was $46.1 \pm 91.9 \mathrm{ng} / \mathrm{ml}$ ranging from 4 to 625 . Twenty-two (36.7 percent) cases had PSA level less than 15.0 $\mathrm{ng} / \mathrm{ml}$. Merely five (8.3percent) cases had PSA level more than $75 \mathrm{ng} / \mathrm{ml}$ beside most of twenty-seven( 45 percent) cases had the level from 15 to $45 \mathrm{ng} / \mathrm{ml}$. PSA level for both lesions hyperplasia and carcinoma were also compared. Difference remained significant $(\mathrm{p}=$ 0.002) statistically. Results found here are in accordance with the findings of study by Cabarkapa et al. ${ }^{14}$ Frequency of micturition was a common clinical symptom, absent in maximum (76.2 percent) cases of prostate adenocarcinoma, whereas hyperplasia cases complaint of frequency to certain amount. p-value observed was less than 0.001. In the same manner, the adenocarcinoma cases had no symptom of urinary retention or very mild retention of urine, whereas in hyperplasia of prostate, merely single case didn't show symptoms of retention and 67 percent show moderate and severe retention. This difference was once more significant with $\mathrm{p}$-value less than 0.001 . In adenocarcinoma cases hematuria was the symptom established in (71.4 percent) cases. Our results are similar with study conducted in 2008 by Khan. ${ }^{19}$

In this study, identified on the basis of eosin and hematoxylin staining, 21 cases of prostatic carcinoma whereas 39 cases of prostate hyperplasia were stained with monoclonal antibody (p63) by standard heatinduced retrieval as well as avidin-biotin method. Hyperplasia and carcinoma of the prostate showed expression with p63. It was established that p63 did not exist in any case of carcinoma however 39 cases of prostatic hyperplasia exhibited positive, nuclear staining pattern. Our results are in accordance with the study in which they observed that there were persistent basal cells staining with p63, of benign and atrophic lesions, and complete lack of basal cells when stained with p63 in prostatic carcinoma. ${ }^{10}$

In a recent study Popkov VM et al (2013) comparatively assessed the molecular markers and concluded a high histochemical score of P63 in a group of patients having prostatic hyperplasia $(\mathrm{Hs}=91)$ and prostatitis $(\mathrm{Hs}=83)$ where some basal cells are intact for 
the positive expression of the P63 and very low score for the carcinoma of the prostate $(\mathrm{Hs}=17) .{ }^{18}$

A study showed the effects of p63 deficiency in the development of the epithelial organs, namely the agenesis of the squamous epithelia, mammary, Salivary, and lacrimal glands. It was demonstrated a very weak expression of the p63 in a series of 130 prostatic carcinomas and in prostate cancer cell line. ${ }^{20}$ In another study a case of atypical adenomatous hyperplasia or adenosis of the prostate showed positive staining of the patchy basal cells and highlighted the immunostaining with p63 in the accurate diagnosis of the prostatic adenosis, a benign mimicker of prostate adenocarcinoma. ${ }^{21}$ These outcomes are also similar with Rashed who conducted comprehensive investigation in 2012. Fifty needle biopsy samples with p63 expression, comprising thirty with small foci of prostatic adenocarcinomas and twenty benign prostates $(<1 \mathrm{~mm}$ or $<5 \%$ of needle core tissue) were stained by $\mathrm{p} 63 .{ }^{22}$ Outcomes of thirty cases of small foci of prostatic adenocarcinomas remained negative for basal cell staining p63 (nuclear stain). p63 positivity was found in all the benign glands of prostate and they were recognized markedly. So it was established from present study that p63 might aid in diagnostic precision and this assisted to avoid taking new biopsies in finding small foci of carcinoma of prostrate. ${ }^{23}$

Current study similarly exhibited comparable findings with other studies where p63 responded with basal cells in ninety eight percent cases (254 out of 259 cases showed positive result). The concentration of nuclear staining wasn't dependent on the techniques of fixation. In atrophic and benign lesions, ten to hundred percent persistent basal cell staining was noted with p63. All cases of prostatic carcinomaremained negative for $\mathrm{p} 63 .{ }^{24}$

\section{Conclusion}

In this study, all benign cases were positive for immunohistochemical expression of P63 while all cases of carcinoma expressed negative staining pattern with p63. Immunostaining with p63 escalates the diagnostic yield, consequently it may be used as a valuable tool in differential diagnosis of prostatic carcinoma.

\section{References}

1. Kim EH, Larson JA, Andriole, GL: Management of Benign Prostatic Hyperplasia. Annual Review of Medi- cine, 2016; 6 (7): 137-51.

2. Ud Din N, Qureshi A, Mansoor S. Utility of p63 immunohistochemical stain in differentiating urothelial carcinomas from adenocarcinomas of prostate. Indian $\mathbf{J}$ Pathol Microbiol. 2011; 54: 59-62.

3. Sarma, AV, Wei JT. Clinical practice. Benign prostatic hyperplasia and lower urinary tract symptoms. N Eng $\mathbf{J}$ of Med. 2012; 367 (3): 248-57.

4. Parsons JK. Benign prostatic hyperplasia and male lower urinary tract symptoms: epidemiology and risk factors. Current Bladder Dysfunction Report, 2010; 5: 212-8.

5. Gacci, M. Metabolic syndrome and benign prostatic enlargement: a systematic review and meta-analysis". BJU International, 2015; 115 (1): 24-31.

6. Afroz T, Radha S. Efficacy of immunohistochemistry in prostate needle biopsies. Journal of Evidence Based Medcal. Healthcare, 2016; 3 (82): 4470-4473.

7. Cunningham GR, Kadmon D. Epidemiology and pathogenesis of benign prostatic hyperplasia. Up To Date, 2013.

8. Bhurgri Y, Kayani N, Pervez S, Ahmed R, Tahir I, Afif M. Incidence and Trends of Prostate Cancer in Karachi South. Asian Pac J Cancer Pre. 2009; 10: 45-8.

9. Baig MK, Hassan U, Mansoor S. Role of p63 in differentiating morphologically ambiguous lesions of prostate. J of Coll of Phy\&Surg. 2012; 22 (12): 773-777.

10. Kalantari MR, Anvari K, Jabbari H, Tabrizi FV. p63 is more sensitive and specific than $34 \beta E 12$ to differentiate adenocarcinoma of prostate from cancer mimickers. Iran J of Med Science, 2014; 17 (7): 497-501.

11. Singh V, Manu V, Malik A, Dutta V, Mani N S, Patrikar S. Diagnostic utility of p63 and $\alpha$-methyl acyl Co A racemase in resolving suspicious foci in prostatic needle biopsy and transurethral resection of prostate specimens. J of Ca Res Th. 2014; 10: 686-92.

12. V. Dötsch F, Bernassola D, Coutandin E, CandiG. Melino. p63 and p73, the Ancestors of p53.Cold Spring Harb Perspect Biol. 2010; 2 (9).

13. Chastain EC, Oliva IV, Osunkoya AO. Utility of p63 and high molecular weight cytokeratin in the distinction between urothelial carcinoma with prostatic stromal invasion and urothelial carcinoma with colonization of prostatic ducts and acini. Pathology, 2012; 44 (3): 199203.

14. Cabarkapa S, Perera M, McGrath S, Lawrentschuk N. Prostate cancer screening with prostate-specific antigen: A guide to the guidelines. Prostate International, 2016; 314 (4): 125-9.

15. Haines IE. Prostate-specific antigen screening for prostate cancer and the risk of overt metastatic disease at presentation. Cancer, 2013; 119 (5): 113.

16. Begum Z, Attar AH, Tengli MB, Ahmed MM. Study of Various Histopathological Patterns in Turp Specimens and Incidental Detection of Carcinoma Prostate. Ind J of Path \& On. 2015; 2 (4): 303-8. 
17. Epstein JI. Diagnosis of limited adenocarcinoma of the prostate. Histopathology, 2012; 60 (1): 28-40.

18. Popkov VM, Maslyakova GN, Voronina ES. Immunohistochemical characteristics in diagnostics of prostate diseases. Russian Open Med J. 2013; 2 (1): 01-09.

19. Khan IA, Nasir M, Akbar M, Khattack I, Khan A, Jan A. Carcinoma of prostate in clinically benign enlarged gland. J Ayub Med Coll. 2008; 20 (2): 90-2.

20. Tan HL, Haffner MC, Esopi DM, Vaghasia AM, Giannico GA,Ross HM, et al. Prostate adenocarcinomas aberrantly expressing p63 are molecularly distinct from usual-type prostatic adenocarcinomas. Mod Path. 2015; 28 (3): 446-56.

21. Kumbar RK, Karibasappa GN, Dravid NV, Patil A. Premalignant Lesions of Prostate and Its Association with Nodular Hyperplasia and Carcinoma of Prostate: A Histomorphological Study. Ann of Path\& Lab Med. 2016; 3 (1): 33-40.

22. Rashed HE, Kateb I. Evaluation of minimal prostate cancer in needle biopsy specimens using AMACR (P504S), P63 and KI67. Marsland Press, 2012; 9: 12-2.

23. Epstein JI, AllsbrookJr WC, Amin MB, Egevad LL, ISUP Grading Committee. The 2005 International Society of Urological Pathology (ISUP) consensus conference on Gleason grading of prostatic carcinoma. Am $\mathrm{J}$ of Surg Path. 2005; 29 (9): 1228-42.

24. Wilkins A, Dearnaley D, Somaiah N. Genomic and histopathological tissue biomarkers that predict radiotherapy response in localised prostate cancer. Bio Med Res Int. 2015: 1-9. 